Original Research Paper

\title{
Direct Analysis of Six Pharmaceuticals using Online Solid Phase Extraction Liquid Chromatography
}

\author{
Siti Norbayu Mohd Subari, Rozita Osman and Norashikin Saim \\ Faculty of Applied Sciences, Universiti Teknologi MARA, 40450 Shah Alam, Malaysia
}

\author{
Article history \\ Received: 26-08-2016 \\ Revised: 03-01-2017 \\ Accepted: 28-03-2017 \\ Corresponding Author: \\ Rozita Osman \\ and \\ Norashikin Saim \\ Faculty of Applied Sciences, \\ Universiti Teknologi MARA, \\ 40450 Shah Alam, Malaysia \\ Email: noras691@salam.uitm.edu.my \\ rozit471@salam.uitm.edu.my
}

\begin{abstract}
In this study, three parameters (sample volume, cleanup and elution step) in large volume injection online Solid Phase Extraction Liquid Chromatography with diode array detection (SPE-LC) were optimized for the determination of six pharmaceuticals in wastewater samples. Preconcentration and separation were carried out using 2 columns, Dionex Ion Pac AG14A and Acclaim Polar Advantage II. Response Surface Methodology (RSM) was employed for the optimization of cleanup step (mobile phase composition and valve switching time). The optimum conditions obtained were as follows: Sample volume of $10.0 \mathrm{~mL}$ and cleanup with acetonitrile and ultrapure water $(5: 95)$ for $1.0 \mathrm{~min}$. The method showed good recovery $(82.91-107.7 \%)$, precision $(0.35-8.26 \%)$ and linearity $\left(\mathrm{R}^{2}>0.99\right)$. The limit of detection was between 3.5 and $11.7 \mu \mathrm{g} \mathrm{L}^{-1}$. The proposed method is rapid, simple and sensitive for trace analysis of pharmaceuticals in water samples.
\end{abstract}

Keywords: Online SPE-LC, Optimization, Water Sample, Pharmaceuticals

\section{Introduction}

In recent years, the occurrence of pharmaceuticals in the aquatic environment has raised concerns (Cardoso et al., 2014; Devier et al., 2013; Lindberg et al., 2014; Repice et al., 2013; Schaider et al., 2014; Vulliet and Cren-Olive, 2011). Pharmaceuticals and related compounds enter the water compartment mainly through municipal wastewater, hospital waste and pharmaceutical industries effluent (Golovko et al., 2014; Verlicchi et al., 2010). They may pass through the conventional water treatment plant and eventually, presence in drinking water (Rivera-Utrilla et al., 2013).

As a result of their occurrence, analytical techniques for trace analysis of wide range pharmaceuticals in water samples, such as wastewater, has been extensively investigated for better efficiency and sensitivity (Buchberger, 2011; Ding et al., 2013; Pailler et al., 2009; Pavlović et al., 2007; Robles-Molina et al., 2014; Yu and $\mathrm{Wu}, 2011)$. The concentration of detected pharmaceuticals in wastewater dependson type of treatment used. Based on recent studies, Baker and Kasprzyk-Hordern (2013) reported high and low concentrations of caffeine in influent wastewater sample (23.77 $\left.\mu \mathrm{g} \mathrm{L}^{-1}\right)$ and in effluent $\left(1.74 \mu \mathrm{g} \mathrm{L}^{-1}\right)$.

Solid phase extraction is the most used method for extraction of pharmaceuticals in water samples. However, an alternative to conventional SPE, online Solid Phase
Extraction Liquid Chromatography (SPE-LC) has been getting more attention since it shortens the extraction and analysis time by its automated technique and reduces the sample volume. Switching valve time is used to perform the extraction and separation in online SPE-LC. The on column preconcentration of high sample volume injection (up to $10 \mathrm{~mL}$ ) in online SPE-LC method showed better sensitivity compared to small volume sample injection (Lindberg et al., 2014; Liu et al., 2013). Hence, optimizing Large Volume Sample Injection (LVSI) method, sample loading volume and cleanupsteps need to be considered in developing online solid phase extraction method (Fernández-Ramos et al., 2014). However, sample loading volume should not exceed maximum adsorption capacity of extraction column and cleanup step is required to eliminate interference matrix components. During the cleanup step, the choice of mobile phases and time of valve switching are important factors that influence the extraction recovery (Fernández-Ramos et al., 2014). Response Surface Methodology (RSM) based on a Central Composite Design (CCD) evaluates the effects of variables using minimum number of experiments. This approach has been applied in the optimization of the extraction method and chromatographic separation (Xu et al., 2014; Bezerra et al., 2008).

Our work attempted to develop LVSI online SPE-LC to detect common pharmaceuticals (acetaminophen, 
caffeine, carbamazepine, naproxen, diclofenac and ibuprofen). RSM was applied in determining the optimum composition of mobile phase and valve switching time. The optimized method was validated and applied to wastewater, surface water and upstream water samples.

\section{Experimental}

\section{Chemicals and Materials}

Standard pharmaceuticals (acetaminophen (ACT), caffeine (CAF), carbamazepine (CBZ), naproxen (NAP), ibuprofen (IBU) and diclofenac (DICLO)) and methanesulfonic acid (MSA) were purchased from Sigma-Aldrich (purity assay in range of 98-101\%) (St. Louis, USA). Acetonitrile (ACN) (HPLC grade) was purchased from Merck (Darmstadt, Germany). Hydrochloric acid ( $\mathrm{HCl})$ (37\%) was from Merck, Darmstadt, Germany. Ultrapure water was produced with aBarnstead Nanopure system (Thermo Scientific, USA).

\section{Online Solid Phase Extraction Liquid Chromatography (SPE-LC) System}

Solid phase extraction and chromatographic separation was performed using an automated online SPE-LC Dionex Ultimate 3000 (Sunnyvale, CA, USA) system. The system consists of dual gradient pumps, left and right, a solvent rack with an integrated vacuum degasser, a large volume loop (10.2 $\mathrm{mL})$ autosampler, a thermostated column compartment, two columns (online SPE column and analytical column) and a diode array detector. The online SPE column was an IonPac AG14A RFIC Guard $(4.0 \times 50 \mathrm{~mm})$ (Thermo Scientific USA) and analytical separation was an Acclaim Polar Advantage II ( $5 \mu \mathrm{m}, 120$ $\AA, 4.6 \times 150 \mathrm{~mm}$ ) (Thermo Scientific USA) as the analytical column. The system is equipped with a programmable 6ports/ 2 position switching valve for several modes (loading, washing, elution and separation). Data were processed by the Chromeleon Software v.6.8 (Dionex).

The method used four major steps: Sample loading, cleanup, elution and LC separation. Both pumps ran simultaneously. The flow rate was set at $1 \mathrm{~mL} \mathrm{~min}^{-1}$ throughout the analysis andtemperature was set at a $40^{\circ} \mathrm{C}$.

\section{Sample Loading and Cleanup}

About $12 \mathrm{~mL}$ water sample was drawn into high volume loop $(10 \mathrm{~mL})$ by a syringe from a $25 \mathrm{~mL}$ vial. The sample loop was overfilled with water sample to eliminate wash solution presence in sample loop and to ensure only water sample inside the sample loop. In the sample loading step, $10 \mathrm{~mL}$ water sample was loaded onto online SPE column (IonPac AG14A Guard $(4.0 \times 50 \mathrm{~mm}$, Thermo Scientific USA) with the left pump using the conditioning solution (10 mM MSA in $\left.\mathrm{H}_{2} \mathrm{O}\right)$ at flow rate of $1 \mathrm{~mL}$ $\mathrm{min}^{-1}$. After sample loading, the valve was switched to cleanup step using the cleanup mobile phase (ACN: 10
mM MSA, 5:95 (v/v) and kept for $1.0 \mathrm{~min}$ to remove any possible impurities retained together with analytes.

\section{Elution and LC Separation}

After cleanup, the valve was switched to connect the SPE column with the analytical column to elute analytes from SPE column into analytical column (Acclaim Polar Advantage II, $5 \mu \mathrm{m}, 120 \AA, 4.6 \times 150 \mathrm{~mm}$, Thermo Scientific USA), where the separation occurred simultaneously. The elution startedwith LC mobile phase at ACN: $10 \mathrm{mM}$ MSA (30:70) followed by a linear gradient to ACN: $10 \mathrm{mM}$ MSA (70:30). Then, the valve was switched to disconnect the online SPE column and analytical column. The separation of analytes continues using LC mobile phase from ACN: 10 mM MSA (70:30) increases to $100 \% \mathrm{ACN}$ in $3 \mathrm{~min}$ and was maintained for 3 min. Meanwhile, the online SPE column was equilibrated with initial conditioning solution. The syringe, injection valve and sample loop were programmed to be washed to eliminate carry over.

\section{Detection}

Pharmaceuticals were detected simultaneously at variouswavelengths. The Diode Array Detector (DAD) was set at $250 \mathrm{~nm}$ (acetaminophen), $280 \mathrm{~nm}$ (caffeine, carbamazepine, ibuprofen) and $220 \mathrm{~nm}$ (diclofenac, naproxen). Identification of pharmaceuticals was based on retention time and Ultraviolet (UV) spectrum of each pharmaceutical.

\section{Preparation of Calibration Standards and Spiked Samples}

The individual stock solution $\left(1 \mathrm{mg} \mathrm{mL}^{-1}\right)$ of pharmaceuticals was prepared in methanol andstored in amber glass bottle. A series of working standard solutions $\left(0.1-50.0 \mu \mathrm{g} \mathrm{L}^{-1}\right)$ were prepared in ultrapure water by dilution prior to analysis to prevent decomposition of analytes. The $\mathrm{pH}$ of the ultrapure water was adjusted to $\mathrm{pH} 2$ with $\mathrm{HCl}(3 \mathrm{M})$ (optimum condition for the analysis). The wastewater (adjusted to $\mathrm{pH}$ 2) was spiked with the standard solutions of the pharmaceuticals to obtain two concentrations (5.0 and $50.0 \mu \mathrm{g} \mathrm{L}^{-1}$ ) for accuracy and precision studies. The chromatogram of standard mixture is shown in Fig. 1.

\section{Sample Collection and Preparation}

Wastewater samples were collected from 15 wastewater treatment plants in Malaysia. Influent wastewater samples were collected using the grab sampling technique and transferred into a 1.0 L high-density polyethylene bottle and were immediately transported to the laboratory. Water samples were acidified to $\mathrm{pH} 2$ using $\mathrm{HCl}(3 \mathrm{M})$. The samples were vacuum filtered using Whatman $0.45 \mu \mathrm{m}$ Glass Fiber (GF/A) (Whatman International Ltd Maidstone, England) to remove suspended solid matter. The filtered water samples were kept in the dark and stored at $4^{\circ} \mathrm{C}$ prior to analysis. 


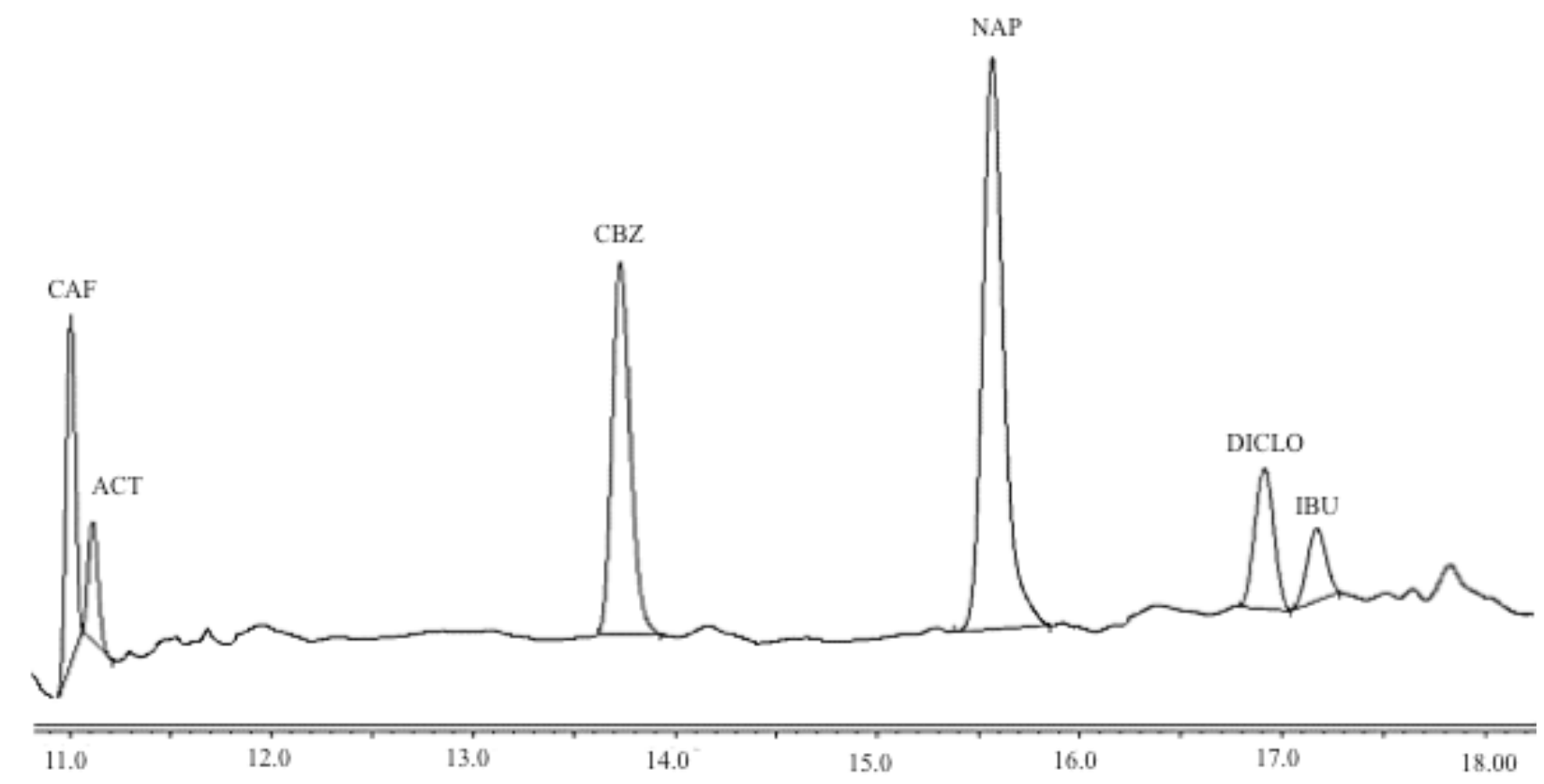

Fig. 1. Chromatogram of standard pharmaceuticals $\left(5 \mu \mathrm{g} \mathrm{L}{ }^{-1}\right)$

Table 1. Results from Central Composite Design (CCD)

\begin{tabular}{|c|c|c|c|c|}
\hline \multirow[b]{2}{*}{ Compounds } & \multicolumn{4}{|l|}{ Model } \\
\hline & Source & $p$-value & Lack of fit & model terms \\
\hline Caffeine & Linear & 0.0117 & 0.4324 & $\mathrm{~A}, \mathrm{~B}$ \\
\hline Acetaminophen & Linear & 0.0154 & 0.3244 & B \\
\hline Carbamazepine & Mean & - & - & - \\
\hline Naproxen & Quadratic & 0.0926 & 0.0583 & - \\
\hline Diclofenac & Quadratic & 0.0792 & 0.9382 & $\mathrm{AB}$ \\
\hline Ibuprofen & Quadratic & 0.3286 & 0.0003 & - \\
\hline
\end{tabular}

*A: Acetonitrile composition; B: Valve switching time

\section{Method Validation}

Method validation was achieved using external calibration curve. Calibration solution of the analytes of $0.1,0.5,1.0,5.0,10.0,50.0 \mu \mathrm{g} \mathrm{L}^{-1}$ were prepared by dilution of working standard mixture of $100 \mu \mathrm{g} \mathrm{L}^{-1}$. Methanesulfonic acid, $10 \mathrm{mM}$ in ultrapure water was added to all samples. The Limit of Detection (LOD) and Limit of Quantification (LOQ) were calculated using linear regression method. Intra-day and inter-day precisions were determined for a concentration of $5 \mu \mathrm{g} \mathrm{L}{ }^{-1}$ of standard mixture in ultrapure water and influent wastewater. Intra-day precision was calculated as RSD in percentage of the peak area of analytes $(n=5)$. The interday precision was determined by analyzing the spiked water over five consecutive days. The accuracy was determined by extraction recoveries of pharmaceuticals in wastewater spiked with standard mixtures $(5$ and $50 \mu \mathrm{g}$ $\left.\mathrm{L}^{-1}\right)$. System suitability studies for the method werecarried out to determine the resolution, theoretical plates, repeatability of retention time and tailing factor.

\section{Results and Discussion}

\section{Online SPE Optimization}

\section{Sample Volume}

The amount of sample pre-concentrated on SPE column affects the sensitivity of the method (Ferreira et al., 2012). The effect of sample loading volume on peak area pharmaceuticals was studied by evaluating 1.0, 5.0 and $10.0 \mathrm{~mL}$ of spiked ultrapure water.The peak area of analytes increases with increasing sample volume, thus increasing the sensitivity of the method (Fig. 2). Therefore, a sample volume of $10 \mathrm{~mL}$ was selected for subsequent optimization study.

\section{Composition of Mobile Phase for Cleanup}

The objective of cleanup step is to remove interferences from the extraction column. Two significant variables for cleanup step, mobile phase composition and valve switching time (Liu et al., 2013) were optimized using central composite design. The 
mobile phase composition of acetonitrile and ultrapure water were evaluated in the range of $5-95 \%$ and the valve switching time was in the range of 1.0-3.0 $\mathrm{min}$. The flow rate of system was maintained at $1 \mathrm{~mL} \min ^{-1}$ to prevent flow inconsistency. The significance of the model was assessed by F-ratio at probability ( $p$ ) of 0.05 , whereby values less than 0.05 indicate the significance of the model. Anon-significant for lack of fit indicated that the model was valid to the spatial influences of variables on the responses (Liu et al., 2013). From the results of six responses (Table 1), caffeine and acetaminophen showed a significant linear model $(\mathrm{p}=0.0117)$ with not significant lack of fit $(p=0.4324)$. The results indicated the adequacy of the applied linear model. The predicted values of caffeine and acetaminophen were calculated using the equation according to the desirability function and compared with experimental value to obtained optimized condition of cleanup step. With desirability function of 0.759 , the composition of acetonitrile to ultrapure water (5:95) and switching valve time of 1.0 min were selected for cleanup step.

The optimized cleanup step was tested using spiked wastewater sample. Figure 3 clearly shows the removal of matrix interferences with cleanup step. The method with cleanup step increased analysis time by $1 \mathrm{~min}$ compared to the method without cleanup step. The proposed online SPE-LC method has successfully separate and detect caffeine in the wastewater sample.

\section{Elution Solvent and Valve Switching Time}

In optimizing elution solvent and valve switching time, various isocratic elution compositions of acetonitrile and $10 \mathrm{mM}$ MSA were studied. Figure 4a-c show that acetaminophen and caffeine were eluted with $20-40 \%$ of ACN, while carbamazepine and naproxen were eluted within $30-70$ and $60-70 \%$ of $\mathrm{ACN}$, respectively.
Diclofenac and ibuprofen were eluted from the column within $60-70 \%$ of ACN. A decrease in composition of 10 $\mathrm{mM}$ MSA with increase of ACN improved the separation of the pharmaceuticals compounds. Hence, a gradient elution approach was performed (Fig. 4d). Optimized gradient elution with initial composition 30:70 (ACN:MSA) to final composition of $70: 30$ (10\% ACN $\min ^{-1}$ ) with switching time of 4 min was able to elute all selected pharmaceuticals (Fig. 4d).

\section{Method Validation}

An external calibration curve was generated using five concentrations of standard mixtures in the range of 0.1 to 50 $0 \mu \mathrm{g} \mathrm{L}^{-1}$ with three replications. Linear curves for each pharmaceutical were obtained between peak areas with a good correlation coefficient $\left(\mathrm{R}^{2}=0.992-0.999\right)$ (Table 2). The sensitivity of method expressed as Limit of Detection (LOD) and Limit of Quantification (LOQ) values were calculated based on linear regression method ranges from 2.5-11.7 and 7.5-35.4 $\mu \mathrm{g} \mathrm{L} \mathrm{L}^{-1}$, respectively. The LOD and LOQ for this method were lower than those reported whereby the LOD and LOQ ranges from 6-74 and $60-200 \mu \mathrm{g} \mathrm{L} \mathrm{L}^{-1}$, respectively (Chandra and Dutt Sharma, 2013; Stafiej et al., 2007). The LOD and LOQ values are also comparable to those reported in the literature (Aguilar-Arteaga et al., 2010). The intra-day and inter-day repeatability were conducted to evaluate the precision of this method. The results were expressed as \% RSD based on the peak area. The intra-day was calculated by performing the analysis of spiked ultrapure water sample and inter-day repeatability study was performed within five consecutive days. The results for intra-day $(0.67-7.87 \%)$ and the inter-day (3.47-9.86\%) (Table 3) showed good precision due to less labor and the fully automatic procedure in the online SPE-LC procedure (Negreira et al., 2013).

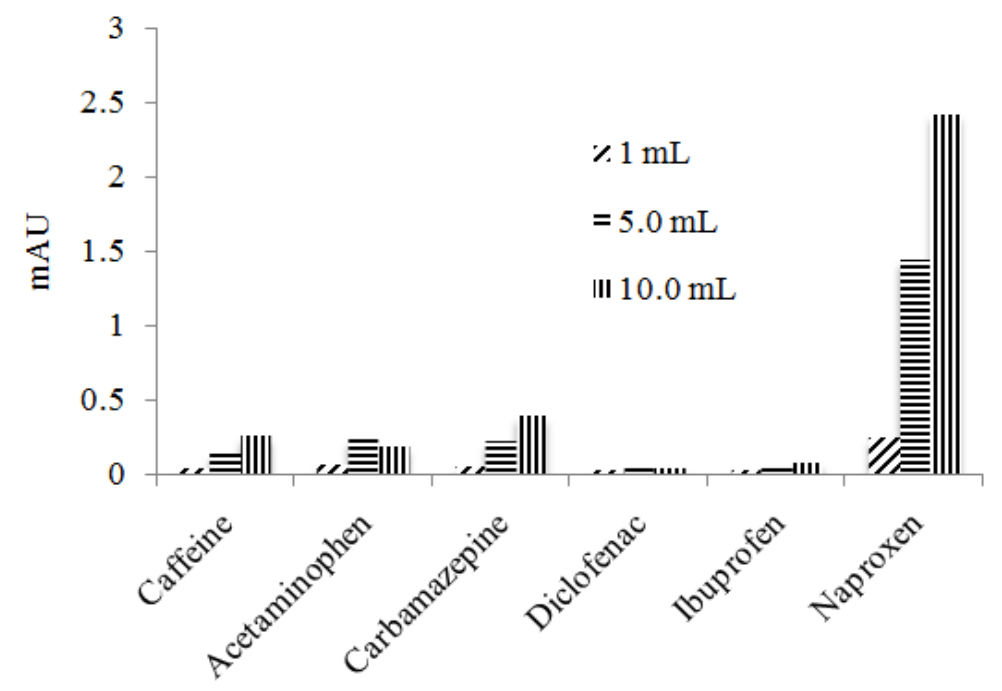

Fig. 2. The effect of different sample volume on the amount of pharmaceuticals 

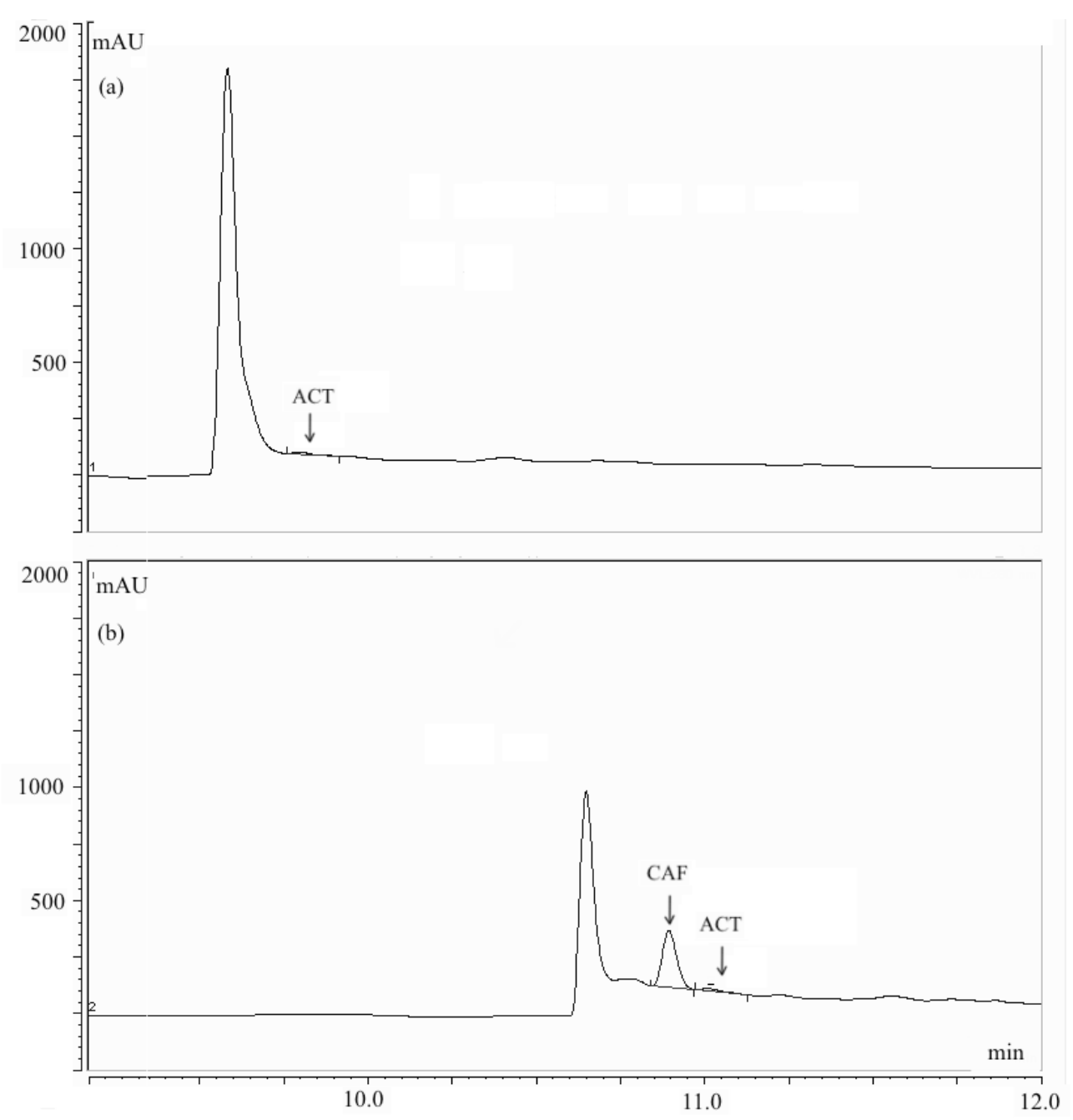

Fig. 3. Chromatogram of spiked wastewater sample without cleanup step (a) and with cleanup step (b) Sample volume: $5 \mathrm{~mL}$

The accuracy was determined by extraction recoveries of pharmaceuticals in wastewater spiked at concentration of 5 and $50 \mu \mathrm{g} \mathrm{L}^{-1}$. Good recoveries of $82.91-107.7 \%$ with $\%$ RSD of $0.35-8.26 \%$ were obtained for all analytes. The result concurred with the study by Al-Odaini et al. (2013). Results for system suitability studies (Table 4) demonstrated the suitability of the developed method for the analysis of the six pharmaceuticals.

\section{Analysis of Water Samples}

The developed method was successfully applied to analyze the six pharmaceuticals in wastewater samples from several influent wastewater treatment plants of Selangor, Malaysia. Concentrations of pharmaceuticals in wastewater are presented in Table 5.

The most frequently detected compounds in influents were acetaminophen, caffeine and diclofenac. Levels detected were in the range of 0.58 to $49.9 \mu \mathrm{g} \mathrm{L}{ }^{-1}$. High concentration of acetaminophen can be explained by its widespread use as an effective painkiller in Malaysia. Acetaminophen (commercially known as paracetamol) and aspirin are the most popular analgesics, available over the counter medication and no prescription is needed upon purchased (Al-Odaini et al., 2013; Papageorgiou et al., 2016). Caffeine was present in all influent samples as it is used in beverages and food as a stimulant. Previous studies reported higher concentration for acetaminophen $\left(134 \mu \mathrm{g} \mathrm{L}^{-1}\right)$ (Gracia-Lor et al., 2012) and caffeine $\left(96.6 \mu \mathrm{g} \mathrm{L} \mathrm{L}^{-1}\right.$ ) (Kosma et al., 2014) in influents. The concentration of diclofenac in influent samples in this study was comparable or higher than maximum concentration observed by Kosma et al. (2014) (5.16 $\mu \mathrm{g} \mathrm{L}^{-1}$ ) and Papageorgiou et al. (2016) $\left(4.87 \mu \mathrm{g} \mathrm{L}^{-1}\right)$. Carbamazepine, naproxen and ibuprofen were not detected at concentration maybe below the LOD (3.5-5.7 $\left.\mu \mathrm{g} \mathrm{L}^{-1}\right)$ of the developed method. Very low concentration of carbamazepine, naproxen and ibuprofen were reported by other studies ranged from 0.07-3.0 $\mathrm{g} \mathrm{L}^{-1}$ (Behera et al., 2011; Blair et al., 2013). 

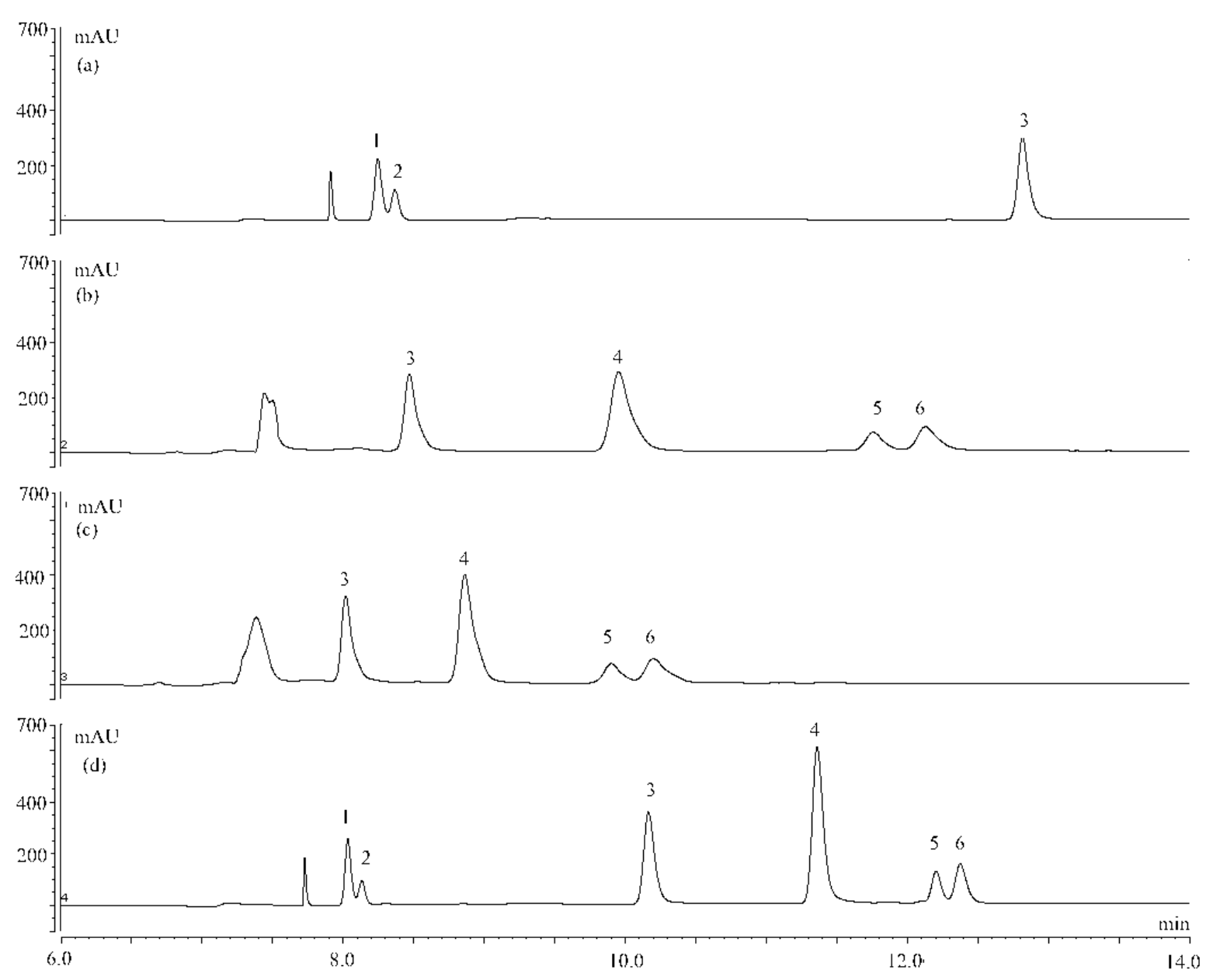

Fig. 4. Chromatograms of isocratic elution, (a) 30\% ACN: 70\% MSA; (b) 60\% ACN: $40 \%$ MSA; (c) $70 \%$ ACN: $30 \%$ MSA and gradient elution (d) 30 to $70 \%$ of ACN: 70 to 30\% MSA. 1: Caffeine, 2: Acetaminophen, 3: Carbamazepine, 4: Naproxen, 5: Diclofenac, 6: Ibuprofen

Table 2. Coefficients of determination, linear range, LOD and LOQ

\begin{tabular}{lllll}
\hline Pharmaceutical & Linear range $\left(\mu \mathrm{g} \mathrm{L}^{-1}\right)$ & $\begin{array}{l}\text { Coefficients of } \\
\text { determination }\left(\mathrm{R}^{2}\right)\end{array}$ & $\left.\mathrm{LOD}(\mu \mathrm{g} \mathrm{L})^{-1}\right)$ & $\left.\mathrm{LOQ}(\mu \mathrm{g} \mathrm{L})^{-1}\right)$ \\
\hline Acetaminophen & $0.1-50$ & 0.995 & 11.7 & 35.4 \\
Caffeine & $0.1-50$ & 0.999 & 2.5 & 7.5 \\
Carbamazepine & $0.1-50$ & 0.996 & 5.7 & 17.4 \\
Diclofenac & $0.5-50$ & 0.997 & 4.2 & 12.6 \\
Ibuprofen & $0.1-50$ & 0.998 & 3.5 & 10.5 \\
Naproxen & $0.1-50$ & 0.999 & 5.5 & 16.7 \\
\hline
\end{tabular}

Table 3. Accuracy and reproducibility (\%RSD) in spiked wastewater

\begin{tabular}{|c|c|c|c|c|}
\hline \multirow[b]{2}{*}{ Pharmaceutical } & \multicolumn{2}{|l|}{ Recovery (\%) } & \multirow[b]{2}{*}{$\begin{array}{l}\text { Intra-day }{ }^{\mathrm{b}} \\
50\left(\mu \mathrm{g} \mathrm{L}^{-1}\right)\end{array}$} & \multirow[b]{2}{*}{$\begin{array}{l}\text { Inter-day }{ }^{\mathrm{b}} \\
50\left(\mu \mathrm{g} \mathrm{L}^{-1}\right)\end{array}$} \\
\hline & $5\left(\mu \mathrm{g} \mathrm{L}^{-1}\right)$ & $50\left(\mu \mathrm{g} \mathrm{L}^{-1}\right)$ & & \\
\hline Acetaminophen & $107.7(0.8)$ & $95.26(1.38)$ & 4.54 & 9.86 \\
\hline Caffeine & $106.8(0.72)$ & 93.74 (3.99) & 5.45 & 3.59 \\
\hline Carbamazepine & $82.91(4.41)$ & $96.62(1.05)$ & 7.87 & 6.28 \\
\hline Naproxen & $98.45(1.42)$ & $92.20(1.65)$ & 1.37 & 3.70 \\
\hline Diclofenac & $98.56(6.13)$ & $89.75(8.26)$ & 4.92 & 3.47 \\
\hline Ibuprofen & $102.4(6.05)$ & $83.67(0.35)$ & 0.67 & 5.76 \\
\hline
\end{tabular}

*RSD (\%) value is in bracket

${ }^{b} \mathrm{n}=5$ 
Table 4. System suitability studies

\begin{tabular}{llll}
\hline Pharmaceutical & Resolution & Theoretical plates & Tailing factor \\
\hline Acetaminophen & 16.4 & 175266 & 0.75 \\
Caffeine & 6.14 & 165311 & 0.90 \\
Carbamazepine & 8.32 & 71053 & 1.20 \\
Diclofenac & 1.08 & 93323 & 0.86 \\
Ibuprofen & - & 54558 & 0.86 \\
Naproxen & 5.793 & 65263 & 1.00 \\
\hline
\end{tabular}

Table 5. Concentrations $\left(\mu \mathrm{g} \mathrm{L}^{-1}\right)$ of pharmaceuticals in samples

\begin{tabular}{|c|c|c|c|c|c|c|}
\hline \multirow[b]{2}{*}{ Sampling site } & \multicolumn{6}{|c|}{ Compounds } \\
\hline & Caffeine & Acetaminophen & Carbamazepine & Naproxen & Ibuprofen & Diclofenac \\
\hline S1 & 14.21 & 10.97 & n.d & n.d & n.d & 2.36 \\
\hline $\mathrm{S} 2$ & 7.78 & 41.65 & n.d & n.d & n.d & 12.82 \\
\hline S3 & 0.58 & 39.01 & n.d & n.d & n.d & n.d \\
\hline S4 & 8.13 & 11.05 & n.d & n.d & n.d & n.d \\
\hline S5 & 7.78 & 6.19 & n.d & n.d & n.d & 8.59 \\
\hline S6 & 7.70 & 44.66 & n.d & n.d & n.d & n.d \\
\hline S7 & 4.89 & 12.05 & n.d & n.d & n.d & n.d \\
\hline S8 & 9.51 & 19.94 & n.d & n.d & n.d & 24.30 \\
\hline S9 & 5.54 & 19.94 & n.d & n.d & n.d & 1.66 \\
\hline $\mathrm{S} 10$ & 11.87 & 8.83 & n.d & n.d & n.d & n.d \\
\hline S11 & 7.34 & 49.97 & n.d & n.d & n.d & 2.59 \\
\hline $\mathrm{S} 12$ & 8.51 & 9.14 & n.d & n.d & n.d & 2.06 \\
\hline $\mathrm{S} 13$ & 6.49 & 9.09 & n.d & n.d & n.d & 13.62 \\
\hline S14 & 15.69 & 12.53 & n.d & n.d & n.d & n.d \\
\hline S15 & 8.30 & 9.45 & n.d & n.d & n.d & 1.29 \\
\hline
\end{tabular}

*n.d: Non detected (below the detection limit)

\section{Conclusion}

The online SPE-LC method was able to provide rapid analysis for pharmaceuticals in wastewater with good reproducibility and accuracy. As the sensitivity obtained is within $\mu \mathrm{g} \mathrm{L}^{-1}$ level, the method is therefore suitable for trace analysis. Large volume sample injection improves sensitivity of the method while online sample preconcentration reduce pretreatment and analysis time. Column switching system allows automated sample preparation and separation without manual labor thus reducing human error. The IonPacAG14A column could be used repeatedly under proposed experimental conditions for over 300 injections of $10 \mathrm{~mL}$ of environmental water samples.

\section{Acknowledgement}

The authors would like to acknowledge the financial support obtained from Organisation for the Prohibition of Chemical Weapons (OCPW) [L/ICA/ICB/170997/11]; and Research Management Institute (RMI) Universiti Teknologi MARA [100RMI/INT 16/6/2 (10/2011)].

\section{Author's Contributions}

Siti Norbayu Mohd Subari: Performed the method development experiments, analyzed the data and wrote the manuscript.
Norashikin Saim: Guided the experimental work and revised the writing of manuscript.

Rozita Osman: Guided the experimental work and revised the writing of manuscript.

\section{Conflicts of Interest}

The authors declare no conflicts of interest.

\section{References}

Aguilar-Arteaga, K., J.A. Rodriguez, J.M. Miranda, J. Medina and E. Barrado, 2010. Determination of non-steroidal anti-inflammatory drugs in wastewaters by magnetic matrix solid phase dispersion-HPLC. Talanta, 80: 1152-1157.

DOI: 10.1016/j.talanta.2009.08.042

Al-Odaini, N.A., M.P. Zakaria, M.I. Yaziz, S. Surif and M. Abdulghani, 2013. The occurrence of human pharmaceuticals in wastewater effluents and surface water of Langat River and its tributaries, Malaysia. Int. J. Environ. Analytical Chem., 93: 245-264. DOI: 10.1080/03067319.2011.592949

Baker, D.R. and B. Kasprzyk-Hordern, 2013. Spatial and temporal occurrence of pharmaceuticals and illicit drugs in the aqueous environment and during wastewater treatment: New developments. Sci. Total Environ., 454-455: 442-456. DOI: $10.1016 /$ j.scitotenv.2013.03.043 
Behera, S.K., H.W. Kim, J.E. Oh and H.S. Park, 2011. Occurrence and removal of antibiotics, hormones and several other pharmaceuticals in wastewater treatment plants of the largest industrial city of Korea. Sci. Total Environ., 409: 4351-4360. DOI: 10.1016/j.scitotenv.2011.07.015

Bezerra, M.A., R.E. Santelli, E.P. Oliveira, L.S. Villar and L.A. Escaleira, 2008. Response Surface Methodology (RSM) as a tool for optimization in analytical chemistry. Talanta, 76: 965-977.

DOI: $10.1016 /$ j.talanta.2008.05.019

Blair, B.D., J.P. Crago, C.J. Hedman, R.J. Treguer and C. Magruder et al., 2013. Evaluation of a model for the removal of pharmaceuticals, personal care products and hormones from wastewater. Sci. Total Environ., 444: 515-521.

DOI: $10.1016 /$ j.scitotenv.2012.11.103

Buchberger, W.W., 2011. Current approaches to trace analysis of pharmaceuticals and personal care products in the environment. J. Chromatography A, 1218: 603-618. DOI: 10.1016/j.chroma.2010.10.040

Cardoso, O., J.M. Porcher and W. Sanchez, 2014. Factory-discharged pharmaceuticals could be a relevant source of aquatic environment contamination: Review of evidence and need for knowledge. Chemosphere, 115: 20-30.

DOI: $10.1016 /$ j.chemosphere.2014.02.004

Chandra, R. and K. Dutt Sharma, 2013. Quantitative determination of paracetamol and caffeine from formulated tablets by reversed phase-HPLC separation technique. Int. J. Chromatographic Sci., 3: 31-34.

Devier, M.H., K. Le Menach, L. Viglino, L. Di Gioia and P. Lachassagne et al., 2013. Ultra-trace analysis of hormones, pharmaceutical substances, alkylphenols and phthalates in two French natural mineral waters. Sci. Total Environ., 443: 621-632. DOI: $10.1016 /$ j.scitotenv.2012.10.015

Ding, Y., B.J. Teppen, S.A. Boyd and H. Li, 2013. Measurement of associations of pharmaceuticals with dissolved humic substances using solid phase extraction. Chemosphere, 91: 314-319.

DOI: 10.1016/j.chemosphere.2012.11.039

Fernández-Ramos, C., D. Satínský, B. Śmídová and P. Solich, 2014. Analysis of trace organic compounds in environmental, food and biological matrices using large-volume sample injection in column-switching liquid chromatography. TrAC Trends Analytical Chem., 62: 69-85.

DOI: $10.1016 /$ j.trac.2014.07.008

Ferreira, S.L., R.E. Bruns, E.G. da Silva, W.N. Dos Santos and C.M. Quintella et al., 2012. Statistical designs and response surface techniques for the optimization of chromatographic systems. J. Chromatography A, 1158: 2-14.

DOI: $10.1016 /$ j.chroma.2007.03.051
Golovko, O., V. Kumar, G. Fedorova, T. Randak and R. Grabic, 2014. Seasonal changes in antibiotics, antidepressants/psychiatric drugs, antihistamines and lipid regulators in a wastewater treatment plant. Chemosphere, 111: 418-426.

DOI: $10.1016 /$ j.chemosphere.2014.03.132

Gracia-Lor, E., J.V. Sancho, R. Serrano and F. Hernandez, 2012. Occurrence and removal of pharmaceuticals in wastewater treatment plants at the Spanish Mediterranean area of Valencia. Chemosphere, 87: 453-462.

DOI: $10.1016 /$ j.chemosphere.2011.12.025

Kosma, C.I., D.A. Lambropoulou and T.A. Albanis, 2014. Investigation of PPCPs in wastewater treatment plants in Greece: Occurrence, removal and environmental risk assessment. Sci. Total Environ., 466-467: 421-438.

DOI: $10.1016 /$ j.scitotenv.2013.07.044

Lindberg, R.H., M. Ostman, U. Olofsson, R. Grabic and J. Fick, 2014. Occurrence and behaviour of 105 active pharmaceutical ingredients in sewage waters of a municipal sewer collection system. Water Res., 58C: 221-229. DOI: 10.1016/j.watres.2014.03.076

Liu, L., Y.B. Wen, K.N. Liu, L. Sun and M. Wu et al., 2013. Optimization of on-line solid phase extraction and HPLC conditions using response surface methodology for determination of WM-5 in mouse plasma and its application to pharmacokinetic study. J. Chromatography B, 923-924: 8-15.

DOI: 10.1016/j.jchromb.2013.01.024

Negreira, N., M. Lopez de Alda and D. Barcelo, 2013. On-line solid phase extraction-liquid chromatography-tandem mass spectrometry for the determination of 17 cytostatics and metabolites in waste, surface and ground water samples. J. Chromatography A, 1280: 64-74.

DOI: $10.1016 /$ j.chroma.2013.01.031

Pailler, J.Y., A. Krein, L. Pfister, L. Hoffmann and C. Guignard, 2009. Solid phase extraction coupled to liquid chromatography-tandem mass spectrometry analysis of sulfonamides, tetracyclines, analgesics and hormones in surface water and wastewater in Luxembourg. Sci. Total Environ., 407: 4736-4743. DOI: 10.1016/j.scitotenv.2009.04.042

Papageorgiou, M., C. Kosma and D. Lambropoulou, 2016. Seasonal occurrence, removal, mass loading and environmental risk assessment of 55 pharmaceuticals and personal care products in a municipal wastewater treatment plant in Central Greece. Sci. Total Environ., 543: 547-569. DOI: $10.1016 /$ j.scitotenv.2015.11.047

Pavlović, D.M., S. Babić, A.J.M. Horvat and M. Kaštelan-Macan, 2007. Sample preparation in analysis of pharmaceuticals. TrAC Trends Analytical Chem., 26: 1062-1075.

DOI: $10.1016 /$ j.trac.2007.09.010 
Repice, C., M. Dal Grande, R. Maggi and R. Pedrazzani, 2013. Licit and illicit drugs in a wastewater treatment plant in Verona, Italy. Sci. Total Environ., 463-464: 27-34. DOI: 10.1016/j.scitotenv.2013.05.045

Rivera-Utrilla, J., M. Sanchez-Polo, M.A. Ferro-Garcia, G. Prados-Joya and R. Ocampo-Perez, 2013. Pharmaceuticals as emerging contaminants and their removal from water. A review. Chemosphere, 93: 1268-1287.

DOI: $10.1016 /$ j.chemosphere.2013.07.059

Robles-Molina, J., F.J. Lara-Ortega, B. Gilbert-López, J.F. García-Reyes and A. Molina-Díaz, 2014. Multi-residue method for the determination of over 400 priority and emerging pollutants in water and wastewater by solid-phase extraction and liquid chromatography-time-of-flight mass spectrometry. J. Chromatography A, 1350: 30-43. DOI: 10.1016/j.chroma.2014.05.003

Schaider, L.A., R.A. Rudel, J.M. Ackerman, S.C. Dunagan and J.G. Brody, 2014. Pharmaceuticals, perfluorosurfactants and other organic wastewater compounds in public drinking water wells in a shallow sand and gravel aquifer. Sci. Total Environ., 468-469: 384-393. DOI: $10.1016 /$ j.scitotenv.2013.08.067

Stafiej, A., K. Pyrzynska and F. Regan, 2007. Determination of anti-inflammatory drugs and estrogens in water by HPLC with UV detection. J. Separat. Sci., 30: 985-991.

DOI: $10.1002 /$ jssc. 200600433
Verlicchi, P., A. Galletti, M. Petrovic and D. Barceló, 2010. Hospital effluents as a source of emerging pollutants: An overview of micropollutants and sustainable treatment options. J. Hydrol., 389: 416-428.

Vulliet, E. and C. Cren-Olive, 2011. Screening of pharmaceuticals and hormones at the regional scale, in surface and groundwaters intended to human consumption. Environ. Pollut., 159: 2929-2934. DOI: 10.1016/j.envpol.2011.04.033

Xu, H., J. Paxton, J. Lim, Y. Li and Z. Wu, 2014. Development of a gradient high performance liquid chromatography assay for simultaneous analysis of hydrophilic gemcitabine and lipophilic curcumin using a central composite design and its application in liposome development. J. Pharmaceut. Biomed. Analysis, 98: 371-378.

$\mathrm{Yu}, \mathrm{Y}$. and L. Wu, 2011. Comparison of four extraction methods for the analysis of pharmaceuticals in wastewater. J. Chromatography A, 1218: 2483-2489. DOI: 10.1016/j.chroma.2011.02.050 